Social Mobility and Life Satisfaction across European Countries: A Compositional Perspective on Dissociative Consequences of Social Mobility.

Jasper Dhoore ${ }^{1}$, Stijn Daenekindt ${ }^{1,2}$ and Henk Roose ${ }^{1}$

Correspondence: Jasper.Dhoore@ugent.be

1 Department of Sociology, Ghent University, Korte Meer 5, 9000 Ghent, Belgium

2 Department of Public Administration and Sociology, Erasmus University Rotterdam, P.O. Box 1738, 3000 DR Rotterdam, The Netherlands

This document contains the accepted manuscript version of the article. The final publication is available at https://doi.org/10.1007/s11205-019-02083-2.

The final published version of the article can be cited as follows:

Dhoore, J., Daenekindt, S., \& Roose, H. (2019). Social Mobility and Life Satisfaction across European Countries: A Compositional Perspective on Dissociative Consequences of Social Mobility. Social Indicators Research, 144(3), 1257-1272. 


\title{
Social Mobility and Life Satisfaction across European Countries: A Compositional Perspective on Dissociative Consequences of Social Mobility.
}

\begin{abstract}
A classic claim in social mobility effects research holds that social mobility is a disruptive and harmful experience. It has been suggested that the experience of social mobility is less disruptive when mobility at the national level is high, because this increases the social and cultural heterogeneity of social classes, which may facilitate the adaptation to the social class of destination. In this article we empirically test the tenability of this claim for social class mobility and life satisfaction. Using Diagonal Reference Models on data for 44 European countries from the 2008 European Values Study, we find evidence for processes of acculturation: the life satisfaction of socially mobile individuals is associated with the class of origin and destination. There is no evidence for effects of social mobility over and above those of social class position of origin and destination. Interestingly, in contrast to suggestions from the literature, national upward or downward mobility rates do not moderate the effect of social mobility on life satisfaction. This study suggests that class heterogeneity does not influence the difficulty of the adaptation to the social class of destination.
\end{abstract}

Keywords: Quality of life; Subjective well-being; Social class mobility; Acculturation; Dissociation; Comparative sociology

\section{Introduction}

Does social mobility affect an individual's well-being? Ever since Sorokin's (1927) seminal work on social mobility, sociologists have been puzzled regarding the consequences of social mobility for well-being. According to Sorokin (1927), social mobility has a 'dissociative effect' on people: it leads to psychosocial problems, even for social climbers. The idea is that social mobility is a mentally and socially demanding and stressful experience because of the great behavioural and cultural adaptation it requires. The dissociative consequences of social mobility may be reflected in a person's well-being, and more specifically in his/her satisfaction with life (Marshall and Firth 1999; Zang and de Graaf 2016). Life satisfaction is an overall evaluation of someone's life (Diener et al. 1999; Myers and Diener 1995). Sorokin's dissociative thesis portrays social mobility as a disruptive life event (Ellis 
and Lane 1967), the degree of disruption of which may be reflected in someone's evaluation of his/her life and life events. Sorokin (1927) also emphasizes that social mobility leads to psychological strain and psychological problems. Given that life satisfaction is strongly correlated with a dimension of distress, namely depression (Headey et al. 1993), these problems may also be reflected in a person's dissatisfaction with his/her life. In addition, previous studies have successfully employed life satisfaction as an indicator for dissociation (e.g., Hadjar and Samuel 2015; Schuck and Steiber 2017).

The dissociative hypothesis is receiving renewed attention, as indicated by a growing number of recent articles on this issue (e.g., Daenekindt 2017; Houle 2011; Houle and Martin 2011; Präg and Richards 2018; Zang and de Graaf 2016; Zhao et al. 2017); but in general, these studies present little evidence for Sorokin's dissociative hypothesis. Apart from some exceptions (see Hadjar and Samuel 2015; Marshall and Firth 1999; Schuck and Steiber 2017), most previous studies focus on single countries to examine the dissociative effects of social mobility, thereby disregarding the role of the context. As various authors suggest that the consequences of social mobility will be more pronounced in certain contexts (e.g., Germani 1966; Goldthorpe 1987; Kessin 1971), the lack of focus on context is surprising. The dissociative effects of social mobility may be dependent upon national social mobility rates. Socially mobile individuals can transfer some of the social and cultural characteristics of their social position of origin into their destination class (Germani 1966; Goldthorpe 1987; see also Sorokin 1927). Therefore, high mobility rates can decrease class differences and thus reduce the detrimental consequences of needing to adapt to the new position (Germani 1966). According to Goldthorpe (1987) high mobility rates may also ease the integration of the socially mobile within their new social class by providing the socially mobile with plenty of opportunities for social relationships with other people who have experienced a similar mobility trajectory. This protects the mobile from experiencing social marginality and social isolation.

In this article we investigate (1) if social mobility affects life satisfaction, and (2) if this relationship depends on the rates of upward and downward social mobility at the national level. This study can contribute to research on mobility effects by shedding light on the role the national context plays for the consequences of social mobility on well-being. 


\section{Theoretical background}

\subsection{Dissociative hypothesis}

The theoretical perspective which considers social mobility as a disruptive and detrimental event is called the 'dissociative hypothesis' (Ellis and Lane 1967). This perspective has its origins in the classic work of Sorokin (1927), who saw social mobility as an individual's move out of a familiar social environment into a new context that demands adaptation to different social behavior and norms. The incongruent social worlds require from the socially mobile individual extensive behavioural and cultural adjustments that are often so demanding that "their nervous systems crumble under the burden of the great strains required of them" (Sorokin 1927, p. 515), eventually leading to psychological strain and mental illness. He also claims that social mobility increases social isolation and loneliness, because the socially mobile are disconnected from the social ties of their class of origin and lack the integration in the class of destination that would allow them to develop new intimate social ties, rendering them as "lonely as a socially unattached atom" (Sorokin 1927, p. 523). Sorokin (1927) claims that social mobility thus results in a range of psychological and social problems that may have detrimental consequences for a person's well-being. Considering that both upward and downward mobility imply a disconnection from the social position of origin and an attachment to an unfamiliar position, any change of social positions will provoke these detrimental consequences (Houle 2011).

\subsection{An alternative perspective: the acculturation hypothesis}

While social mobility is a harmful experience from the perspective of Sorokin's (1927) dissociative hypothesis, Blau's (1956) acculturation hypothesis provides an alternative perspective to the consequences of social mobility, in which a persons' well-being is shaped by social class of origin and destination, rather than by social mobility per se. From this perspective social mobility merely involves a process of acculturation to the values and lifestyle typical for the social position of destination (Blau 1956; see also Jackman 1972). However, because the socially mobile may still experience some influences of the conditions of their original social class, both origin and destination have some influence on the socially mobile (Blau 1956). Empirical research demonstrates greater well-being in higher socio-economic positions (e.g., Stansfeld et al. 1998). Therefore, the well-being 
of the downwardly mobile may be better than that of people in their destination class, but may be worse than the well-being of those in their class of origin. Similarly, the well-being of the upwardly mobile may be worse than those in their destination class, but may be better than people in their class of origin.

\subsection{Empirical research on the dissociative thesis}

Early empirical research on the dissociative hypothesis is characterized by mixed findings (Ashford, 1990), with some research supporting the dissociative hypothesis (e.g., Ellis and Lane 1967; Hollingshead et al. 1954), and others rejecting it (e.g., Tumin and Collins 1959). These initial quantitative investigations of the dissociative and acculturation hypotheses have been hampered by methodological barriers (Houle 2011). One of the major methodological obstacles has been to accurately separate the effect of social mobility per se from the effects of social class of origin and destination (Sobel 1981, 1985). It was only with the development of Diagonal Reference Models (DRMs), a statistical technique designed by Sobel (1981), that it became possible to isolate mobility effects from class effects (see also van der Waal et al. 2017). This methodological development has greatly stimulated and enriched research on social mobility, as DRMs allow researchers to include mobility as an independent variable and to successfully investigate the effects of social mobility on a whole range of outcomes, such as political attitudes (e.g., Daenekindt et al. 2017; Nieuwbeerta et al. 2000), attitudes towards ethnic minorities (e.g., Tolsma et al. 2009), cultural tastes and aesthetic preferences (e.g., Daenekindt and Roose 2013 , 2014), and health (e.g., Missinne et al. 2015; van der Waal et al. 2017).

Recent studies that have applied DRMs on intergenerational social mobility find little support for Sorokin's dissociative hypothesis (e.g., Daenekindt 2017; Houle and Martin 2011; Präg and Richards 2018; Zang and de Graaf 2016; Zhao et al. 2017). For instance, in a study on intergenerational social class mobility and psychological distress in the United States, Houle and Martin (2011) find no evidence for dissociative effects of upward or downward social class mobility. They find that men who are upwardly mobile out of the farming class experience less psychological distress than immobile individuals. In a recent study on intergenerational educational mobility in 
Belgium, Daenekindt (2017) finds some evidence for the dissociative effects of downward mobility, but not for upward mobility. Downwardly mobile individuals are shown to experience more social disorientation and more utilitarian individualism than immobile individuals. Upward social mobility is even associated with a lower level of utilitarian individualism. Studies that investigate the consequences of intergenerational social mobility on happiness also provide little evidence for Sorokin's dissociative thesis. For example, Zang and de Graaf (2016) find that intergenerational status rank mobility is not associated with happiness. Zhao et al. (2017) find similar results: upward and downward intergenerational social class mobility have no effect on happiness over and above those of social class of origin and destination. However, it is important to note that the studies from Zang and de Graaf (2016) and Zhao et al. (2017) both focus on the consequences of social mobility in China. Generalizations to the European context are risky.

The subjective experience of social mobility has also been investigated by scholars that use qualitative methods. A well-known example is Goldthorpe's (1987) work in which he uses life history notes to investigate how intergenerational social class mobility is experienced by British men. His results show that upwardly and downwardly mobile men do not experience their social mobility trajectory as socially and psychologically stressful. This rather optimist account of social mobility is contradicted by the results of other qualitative studies (e.g., Friedman 2016; Lubrano 2004; Newman 1988). For example, in his recent qualitative study on intergenerational upward social class mobility in the United Kingdom, Friedman (2016) underlines the complex, ambivalent and often emotionally difficult experience of social mobility. Another example is a qualitative study on intragenerational downward occupational mobility in the United States by Newman (1988). She points at the psychologically and socially damaging impact that sliding down the occupational ladder has.

Although the dissociative consequences of social mobility have recently received increasing attention, cross-national comparisons of these effects are scarce. An exception is a study from Marshall and Firth (1999) in ten countries on satisfaction with different life domains. They find no evidence for effects of social class mobility. Another cross-national study, by Hadjar and Samuel (2015), compares the consequences of social class mobility for life satisfaction in the United Kingdom and Switzerland. These authors find dissociative effects of upward mobility only in the United 
Kingdom, however, they do not control for social class of origin, so the effect of upward mobility may be overestimated. A third exception is a study by Schuck and Steiber (2017) on the impact of intergenerational educational social mobility on life satisfaction. In their study they find that social mobility only affects life satisfaction in countries in Continental Europe. These authors argue that this is because the maintenance of social status is an important component of the social identity of people in Continental Europe. However, these results only apply to respondents aged 25 to 34 in 18 European countries. Generalizations to broader populations are risky.

\subsection{Importance of national mobility rates}

Goldthorpe (1985) distinguishes two different perspectives from which social mobility has traditionally been approached: a hierarchical approach and a social class approach. These perspectives differ in terms of the context in which they define social mobility. These perspectives have their origins in the first mobility studies from the nineteenth century. In the former approach social mobility is defined in the context of a social hierarchy. In this approach social groups are vertically ordered on a hierarchy based on a stratifying principle such as prestige or status. This hierarchy is measured using a continuous scale (Ganzeboom et al. 1992). In the latter approach social mobility is defined in the context of a class structure (Goldthorpe 1985), and individuals are categorized into social classes based on their "relationships within labour markets and production units" (Erikson and Goldthorpe 1992, p. 29). Erikson and Goldthorpe (1992) argue that occupations that hold a similar position on hierarchical scales often have little in common except for their position on this single stratifying principle. Within a class approach on the other hand, it is assumed that members of a social class are to a certain extent homogeneous and different from members of other classes (Erikson and Goldthorpe 1992; see also Ganzeboom et al. 1992). The criteria used to define the homogeneity of the class members depend on the specific class scheme that is employed (Ganzeboom et al. 1992). A central concern of research that employs a social class approach is the influence that social mobility has for the homogeneous composition and stability of social classes (Erikson and Goldthorpe 1985).

A focus on the composition of social classes provides a good starting point to theoretically frame how upward and downward mobility at the national level may affect the individual dissociative 
consequences of social mobility. In a compositional interpretation of social classes, the socio-cultural traits of a social class are considered to be the sum of the characteristics of its members (de Graaf et al. 1995). From this compositional interpretation of social classes it follows that the inflow of people from different class origins can influence the socio-cultural distinctiveness of a social class (Germani 1966; Goldthorpe 1987). For instance, Goldthorpe (1987, p. 344) argues that when new class members are recruited from different social class origins, the internal socio-cultural homogeneity of the recruiting class decreases, because the socially mobile "carry the normative and relational patterns of their class origins into their class of destination". So, social mobility shapes the socio-cultural composition of social classes.

Empirical research presents evidence for the influence of social mobility on the social and cultural distinctiveness of social positions. For example, in his study on class mobility in Britain, Goldthorpe (1987) points at the reduced socio-cultural distinctiveness of the service class because of high rates of upward mobility from different class origins. This was not the case for the working class that was characterized by a homogeneous demographic identity because of homogeneous class recruitment patterns. In his study on the existence of classes in the United States, Kingston (2000) finds that the American class system is characterized by a social heterogeneity in every social class. In a study on social mobility and cultural consumption, van Eijck (1999) suggests that the association between social status and cultural consumption weakens because of the inflow of people with different social origins into the group of the more highly educated.

Several scholars link the composition of social classes to the consequences of social mobility, and argue that high social mobility rates diminish the detrimental consequences of social mobility (e.g., Germani 1966; Goldthorpe 1987; Kessin 1971). This attenuation of the consequences of social mobility via class heterogeneity may be caused by two similar mechanisms. Firstly, according to Germani (1966), an increased socio-cultural heterogeneity in social classes may reduce social class differences. He suggests that the adjustment to the receiving social class will be more conductive to dissociative consequences in societies in which a high degree of discontinuity exists between social classes, in contrast to societies in which class boundaries are blurred. Given that a central assumption of Sorokin's (1927) dissociative hypothesis is that social positions are characterized by distinctive 
behavior, habits and ideas, and that it is the discrepancy between these cultural traits of social classes that cause adaptation problems, the adaptation to the new social position may indeed be less challenging when social classes are less distinct because of high mobility rates.

A second and similar way that high mobility rates and the accompanying class heterogeneity may diminish the dissociative consequences of social mobility is by providing the mobile with plenty of opportunities to form social relationships with others who have had a similar mobility trajectory in their class of destination. This is suggested by Goldthorpe (1987) in his assessment of social mobility and social isolation. Goldthorpe (1987, pp. 199-200) explains his lack of evidence for upward social mobility as a dissociative event that leads to social isolation and social marginality by suggesting that "in present-day Britain the upwardly mobile at least are sufficiently numerous, as a component of the service class, to be able to provide each other ample possibilities for relations of sociability, even supposing it to be the case that they encounter difficulty in forming such relations with members of the service-class core." Thus, high mobility rates into the destination classes of the socially mobile may provide them with plenty of opportunities to form relationships with people who have experienced a similar mobility trajectory. This may prevent the socially mobile from becoming socially isolated. We may also cautiously interpret this idea as a suggestion that an adaptation to the traits of the 'core characteristics' of a social class is not a necessary prerequisite for the mobile to be well-integrated in the class of destination, because he/she is sufficiently surrounded by people with a cultural background similar to his/her own.

Various authors (e.g., Germani 1966; Goldthorpe 1987; Kessin 1971) suggest that the societal context will affect the consequences of social mobility, however, as described above, recent crossnational investigations of the dissociative consequences of social mobility are scarce. In this study we will do a cross-national comparison across European countries. More specifically, we will empirically test the claim that the dissociative consequences of social mobility are dependent on national mobility rates.

\subsection{Hypotheses}


Based on our theoretical framework we have several expectations. On the individual level we distinguish two alternative hypotheses. As previously described, Sorokin (1927) views social mobility as a detrimental event. Life satisfaction captures a person's subjective evaluation of his/her life (Diener et al. 1999; Myers and Diener 1995). The detrimental experience of social mobility may be part of this evaluation and may thus affect a person's life satisfaction. Therefore, in line with Sorokin's dissociative thesis, we hypothesize that the experience of upward and downward mobility leads to a lower level of life satisfaction (hypothesis 1). Following Blau's acculturation thesis, we expect that the life satisfaction of the socially mobile is associated with their social position of origin and destination (hypothesis 2).

We expect that the extent to which social mobility has dissociative effects will depend on national social mobility rates. High rates of national social mobility can increase the social and cultural heterogeneity within social classes. This may ease the social and cultural adaptation to the social class of destination. Because we study social classes from a compositional perspective, and because upward and downward social mobility are both uniquely related to the social class origins of members in different destination classes, we make different hypotheses for the influence of national upward and national downward mobility rates. Because upward mobility transfers social and cultural elements of the origin classes of the upwardly mobile to the destination classes of the upwardly mobile, we expect that upward mobility will have a greater dissociative impact on life satisfaction in countries with lower rates of upward mobility (hypothesis 3). Because downward mobility transfers social and cultural elements of the origin classes of the downwardly mobile to their destination classes, we expect that downward mobility will have a greater dissociative impact on life satisfaction in countries with lower rates of downward mobility (hypothesis 4).

\section{Data and methods}

\subsection{Data}

This study employs cross-national data from the fourth wave of the European Values Study 2008 (EVS 2016). The EVS 2008 contains detailed information on subjective well-being and on the social class position of respondents and their parents. The EVS 2008 covers 46 countries/regions in Europe. 
For most countries a random probability sample of about 1500 individuals aged 18 and over was selected. Response rates range from $24.5 \%$ in Great-Britain to $88.4 \%$ in Montenegro (Brislinger et al. 2011). Northern Cyprus and Northern Ireland are omitted from the analyses because of small sample sizes. The analyses are based on respondents aged 30 and over. This restriction was chosen because respondents aged 30 and over are more likely to have reached occupational maturity (Erikson and Goldthorpe 1992). Respondents with missing values on the included variables are also omitted from the analyses. This results in a final sample of 36960 individuals $^{1}$ in 44 European countries.

\subsection{Measures}

Life satisfaction. Life satisfaction is the cognitive component of subjective well-being and consists of a global cognitive evaluation of someone's life (Diener et al. 1999; Myers and Diener 1995; see also Andrews and Withey 1976). The EVS includes a single-item scale for life satisfaction. Life satisfaction is measured by the question, "All things considered, how satisfied are you with your life as a whole these days?" This question could be answered on a 10-point Likert scale ranging from 1 to 10 , from dissatisfied to satisfied. Mean life satisfaction scores at the country level range from 5.349 in Georgia, to 8.383 in Denmark (see Table 1).

Social class position of origin and destination. In line with the conventional approach in social class research (see Goldthorpe 1983), social position of origin is measured by the social class position the father of a respondent occupied when the respondent was aged 14. For respondents who lived only with their mother when they were 14, the occupational class position of the mother is taken as the social position of origin. Respondents who were not living with any of their parents when they were aged 14 were not selected for the analyses. Social position of destination is measured by the current occupational class position of a respondent.

The EVS provides an extensive eleven-class version of the well-known EGP-scheme (Erikson and Goldthorpe 1992; Erikson et al. 1979). This social class scheme was validated by Evans (1992) and Evans and Mills (1998). In Goldthorpe's (1987) scheme social classes are differentiated based on the shared market and work situations of their members. In the EVS respondents were allocated to

\footnotetext{
${ }^{1}$ This sample size refers to the unweighted number of cases.
} 
social classes based on information on their ISCO-88 score, employment status, and supervisory status (see Ganzeboom and Treiman 1996). To attain sufficient cell frequencies for the statistical analyses we use a three-class collapsed model of the EGP-scheme, which distinguishes between the service class (classes I and II), the intermediate class (classes IIIa, IIIb, IVa, IVb, IVc and V) and the working class (VI, VIIa and VIIb) (Goldthorpe 1987).

A difficulty associated with an occupation-based measure for social position is that not everyone is active on the labour market (Crompton, 1998; Duke and Edgell 1987). For example, some people are unemployed and others, such as older people, may be retired. Duke and Edgell (1987, p. 453) criticize studies that only include people who currently have an occupation for their "restrictive and distorted view of the class structure", because they do not include a large share of the adult population. Marshall et al. (1996) suggest that the economically inactive are still affected by their previous position within the class structure. They found that the class-related characteristics of the economically active are similar to those of the economically inactive. Therefore the social class position of individuals who were not in paid employment at the time of the interview, but who had worked before, was based on their last paid employment. However, this strategy could not be applied to people who had never had an occupation; consequently, people who had never engaged in any paid employment were excluded from the analyses.

Intergenerational upward and downward social class mobility. Social class mobility refers to a situation in which an individual occupies a different social class position than his parents. We define upward mobility as mobility from the working class into the intermediate class and from the working class and intermediate class into the service class. We define downward mobility as mobility in the opposite direction. ${ }^{2}$ Upward and downward social class mobility are included as dummy variables, with immobility serving as the reference category.

\footnotetext{
${ }^{2}$ The eleven-class EGP-scheme is not developed as a hierarchical scale (Erikson and Goldthorpe, 1992; Goldthorpe, 1987). A strategy to derive the vertical ordering of social classes is by consulting external hierarchical criteria (Erikson and Goldthorpe, 1992, p. 44). We applied this strategy by consulting the mean and median International Socio-Economic Index of occupational status scores (ISEI) for the respondents in each social class of destination (for ISEI see Ganzeboom et al. 1992). These results show that our three-class scheme is hierarchical ordered in the following order, from highest to lowest status: (1) service class (mean ISEI $=60.22$; median ISEI = 61.00), (2) intermediate class (mean ISEI = 39.54; median ISEI = 42.00); working class (mean ISEI $=28.61$; median ISEI $=30.00)$.
} 
Upward and downward country level mobility rates. As an indicator for national upward and downward mobility rates the percentages of upward and downwardly mobile individuals at the national level were calculated for each country. Upward mobility rates range from $22.013 \%$ in Turkey, to $46.253 \%$ in Bosnia and Herzegovina, while downward mobility rates range from $9.151 \%$ in Slovak Republic, to $27.803 \%$ in Turkey. To facilitate the cross-national comparative analysis we grouped the countries according to their mobility rates. A stratified approach has already been applied to the crossnational study of the consequences of social mobility in previous research, and proved to be a fruitful way to compare countries when employing DRMs (see Schuck and Steiber 2017). In our study countries were categorized into four equal groups using quartiles based on their upward mobility rates, and four equal groups using quartiles based on the downward mobility rates of the countries (see Table $1)$.

Control variables. ${ }^{3}$ We control for employment status using a categorical variable using the following categories: employed (60.5\%), unemployed (6.2\%), retired/pensioned (25.9\%), student $(0.2 \%)$, keeping house $(4.9 \%)$ and other $(2.2 \%)$. Gender (49.9\% male; $50.1 \%$ female) and age (mean = 51.55; S.D. $=14.45)$ are also included in the analyses as control variables.

[TABLE 1 ABOUT HERE]

\subsection{Methods}

To assess the effects of social mobility we employ DRMs (see Sobel 1981). DRMs are based on the assumption that immobile individuals represent the core characteristics of a social position.

Characteristics of socially mobile individuals (individuals in the off-diagonal cells in the mobility Table) are modelled as the weighted average of the characteristics of immobile individuals in the origin and destination position (individuals in the associated diagonal cells in the mobility table). The equation of our model is represented as:

$Y_{i j k}=p \mu_{i i}+(1-p) \mu_{j j}+\beta_{1} u s m_{i j}+\beta_{2} d s m_{i j}+\sum \beta_{l} x_{i j k l}+e_{i j k}$

Where:

$i=$ social class of origin

$j=$ social class of destination

\footnotetext{
${ }^{3}$ All descriptive statistics for the control variables are based on weighted data.
} 
$k=$ observations

$p=$ weight of origin class

usm = upward social mobility

$d s m=$ downward social mobility

$l=$ covariates

$e=$ error term

In the equation described above $Y_{i j k}$ represents the life satisfaction of respondent $k$ with social class of origin $i$ and social class of destination $j$. The mean life satisfaction scores for class of origin $i$ and class of destination $j$ are represented by the diagonal values $\mu_{i i}$ and $\mu_{j j}$. The relative salience of these diagonal values for the socially mobile is indicated by the origin $(p)$ and destination $(1-p)$ weight parameters. So, the $p$-parameter lies in the interval of 0 to 1 (Sobel 1981). A p-parameter that is significantly greater than 0,5 indicates that the life satisfaction of the socially mobile is mainly influenced by the social class of origin. When a $p$-parameter is significantly less than 0,5 , the social position of destination is the most salient (Sobel 1985). To test if social mobility has effects over and above the relative influence of origin and destination class, mobility variables for upward (usm) and downward social mobility $(d s m)$ are added to the model (Sobel 1981, 1985). By doing this, DRMs align with social mobility theory, which argues that "one is not entitled to discuss "effects" of mobility (or other status discrepancy measures) until he has established that the apparent effect cannot be due merely to a simple combination of effects of the variables used to define mobility' (Duncan 1966, p. 91). Control variables are added to the model as covariates $(l)$. To investigate the moderating impact of social mobility at the national level, we perform separate analyses for each of the country groups based on their mobility rates. Because individuals are clustered within countries, we include $n-1$ country dummies for each of the country groups. By incorporating these country fixed effects, the country level heterogeneity in average life satisfaction is accounted for.

\section{Results}

In Table 2 we provide the results of the DRMs for the countries categorized according to their upward and downward social mobility rates. The diagonal intercepts show that life satisfaction in Europe is clearly stratified according to social class membership. A higher social class position corresponds with more life satisfaction in each of the country groups. This social class gradient is most pronounced in 
the countries that are in the lowest and second quarter according to their downward social mobility rates. For instance, for countries with low downward mobility rates, the score on life satisfaction for immobile individuals who are members of the service class is 6.778 ; for immobile individuals in the working class this score is 6.121 .

The weight parameter of origin provides information about the extent to which the socially mobile reflect the level of life satisfaction characteristic for their social position of origin and destination. For every country group the weight presented is not significantly different from 0.5 . This means that socially mobile people experience levels of life satisfaction that are in between that of their origin and destination position. This is in line with the acculturation hypothesis (hypothesis 2). Thus, both social class of origin and destination appear to be of substantial importance for the life satisfaction of the socially mobile.

Next, we evaluate the parameters for upward and downward social mobility for each of the country groups. These parameters test if upward and downward social mobility are associated with life satisfaction in the different country groups. The results show that upward and downward mobility are not associated with life satisfaction in any of the country groups. This result provides evidence against the dissociative hypothesis (hypothesis 1). Based on these results we also have to reject the countrylevel hypotheses 3 and 4, as upward mobility and downward social class mobility are not associated with life satisfaction, regardless of the national upward and downward mobility rates.

So, in general, our results favour Blau's acculturation hypothesis: the socially mobile partly acculturate to the level of life satisfaction that is typical for the social position of destination. This result applies to each of the country groups.

[TABLE 2 ABOUT HERE]

\section{Discussion}

In this article we investigated whether intergenerational social class mobility is associated with life satisfaction, and whether this relationship depends on the upward and downward social class mobility rates at the national level. 
Our study provides some important findings. We found that life satisfaction is clearly stratified according to social class, with higher social class positions corresponding with greater satisfaction with life. Our results also showed that in Europe, both social class position of origin and destination affect a persons' life satisfaction. As such, our findings endorse Blau's (1956) acculturation thesis, which states that people partly acculturate to the characteristics of their newly acquired social position, but also experience an enduring influence of the social environment in which they were socialized during their childhood. The finding of acculturation processes in Europe reaffirms the evidence Houle (2011) found for the United States. The partial process of acculturation implies that the upwardly mobile do not fully benefit from the same advantages as those who are permanent members of the higher social classes, and that the downwardly mobile do not experience the same disadvantages as permanent members of the lower classes. The socially mobile still carry with them some of the advantages and disadvantages inherent to their social class position of origin.

In line with several previous studies (e.g., Präg and Richards 2018; Zang and de Graaf 2016; Zhao et al. 2017), we do not find any evidence for effects of intergenerational social mobility over and above the effects of social class of origin and social class of destination. This contradicts Sorokin's (1927) picture of social mobility as a disruptive and detrimental event that has a dissociative effect on people. Thus, our finding casts doubt on the tenability of the dissociative hypothesis. Our results suggest that Sorokin may have exaggerated the problems that are involved with the experience of social mobility, as we find that social class mobility is not associated with lower life satisfaction.

Various scholars suggest that mobility rates at the national level will affect the experience of social mobility (e.g., Germani 1966; Goldthorpe 1987; Kessin 1971). We found no evidence for a moderating influence of upward or downward mobility rates at the national level. Notice that we based our analyses on 44 different countries in which upward and downward social mobility varied to a considerable degree. However, we did not find any evidence of effects of social mobility, regardless of the national upward or downward social mobility rates. Therefore, our findings disconfirm the claim that dissociative effects of social mobility will most likely occur when social mobility at the national level is low (see Germani 1966; Goldthorpe 1987; Kessin 1971). Our findings do not support the 
notion of dissociative effects of social mobility that are dependent upon national rates of social class mobility.

So, in contrast to the suggestions in the literature we found no evidence for the dissociative thesis or for a moderating influence of social mobility at the national level. We provide three potential explanations for this lack of evidence. Firstly, both downward and upward social mobility may be sufficiently present in each and every country in Europe to diminish the dissociative consequences of social mobility. Our study showed that upward social mobility rates are fairly substantial in each country in our sample, and although downward social mobility rates are much lower than upward mobility rates, even these low rates may be sufficient to attenuate the dissociative effects of social mobility by reducing class differences and by providing social relationships for the socially mobile. Secondly, the context that affects people's experience of social mobility may not be situated at the country level. Potentially, mobility rates in more local contexts such as regions or neighborhoods are more relevant than the country context for the mobility experience, because they may be more visible for the socially mobile. Therefore, future research should move beyond our focus on the national context and should investigate other contexts that may affect the subjective experience of social mobility.

A third explanation for our lack of evidence for dissociative consequences of social mobility is that people may not be aware of their mobility trajectory. Research shows that individuals who have been defined as objectively mobile often do not perceive their mobility trajectory as such (Duru-Bellat and Kieffer 2008; Kelley and Kelley 2009). However, scholars on mobility consequences often consider peoples' subjective perception of their social mobility trajectory to be an important factor via which social mobility affects individuals (Kelley and Kelley 2009). A lack of a subjective perception of mobility, for instance, may prevent social mobility from having dissociative effects. Future research would benefit from investigating the importance of subjectively defined social mobility for a person's well-being.

A limitation of this study is in the approach that has been used to allocate the origin family to social classes. For respondents who lived with their father and mother when they were 14 years old the EVS 2008 contains information on the occupation of the father but not on the occupation of the 
mother. Therefore, for these respondents, family of origin was classified according to the class position of the occupation of the father. This is in line with the conventional approach within social stratification research to allocate the social class position of a family using the class of the male head of the family (see Erikson 1984; Goldthorpe 1983). From the perspective of the conventional approach, the social class position of the family is not related to the employment status and occupation of the female family member (Sørensen 1994). By applying this conventional approach of classes, our measure of social position of origin may not adequately measure the social class of origin of people. Several alternative approaches exist that take into account the positions of both partners of a couple. For instance, a possibility is to determine the position of the family of origin by the position of the partner with the highest-level class, or to take the average of the positions of both partners (Erikson 1984). These alternative approaches may potentially better grasp the social class position of origin. With our data, we are not able to empirically test these alternatives. However, in a study on educational mobility and dissociation in Belgium, Daenekindt (2017) finds no different conclusions based on these alternative approaches of social position, compared with the conventional approach.

In this article we contributed to existing research on social mobility and well-being by adding a comparative, macro-sociological perspective to the analysis of the effects of social mobility. More specifically, we explored the effects of the rates of upward and downward social mobility at the national level. Rather than differences, our study highlighted similarities in the mobility experience across Europe. Social mobility involves a process of partial acculturation to the destination class, no matter what the national social mobility rates are. We endorse Houle's (2011) argument that evidence for processes of acculturation is an important finding in research on social mobility effects. Our confirmation of the acculturation hypothesis provides evidence for the complex way in which distinct contexts of socialization affect the well-being of the socially mobile. 


\section{References}

Andrews, F. M., \& Withey, S. B. (1976). Social indicators of well-being. New York: Plenum Press.

Ashford, S. (1990). Upward Mobility, Status Inconsistency, and Psychological Health. Journal of Social Psychology, 130(1), 71-76.

Blau, P. M. (1956). Social Mobility and Interpersonal Relations. American Sociological Review, 21(3), 290295.

Brislinger, E., de Nijs Bik, E., Harzenetter, K., Hauser, K., Kampmann, J., Kurti, D., et al. (2011). European Values Study 2008: project and data management. Cologne.

Crompton, R., (1998). Class and Stratification: An Introduction to Current Debates (2nd ed.). Cambridge: Polity Press.

Daenekindt, S. (2017). The Experience of Social Mobility: Social Isolation, Utilitarian Individualism, and Social Disorientation. Social Indicators Research, 133(1), 15-30.

Daenekindt, S., \& Roose, H. (2013). A Mise-en-scene of the Shattered Habitus: The Effect of Social Mobility on Aesthetic Dispositions Towards Films. European Sociological Review, 29(1), 48-59.

Daenekindt, S., \& Roose, H. (2014). Social mobility and cultural dissonance. Poetics, 42, 82-97.

Daenekindt, S., van der Waal, J., \& de Koster, W. (2017). Social mobility and political distrust: cults of gratitude and resentment? Acta Politica, https://doi.org/10.1057/s41269-017-0050-4.

de Graaf, N. D., Nieuwbeerta, P., \& Heath, A. (1995). Class Mobility and Political Preferences: Individual and Contextual Effects. American Journal of Sociology, 100(4), 997-1027.

Diener, E., Suh, E. M., Lucas, R. E., \& Smith, H. L. (1999). Subjective Well-Being: Three Decades of Progress. Psychological bulletin, 125(2), 276-302.

Duke, V., \& Edgell, S. (1987). The Operationalisation of Class in British Sociology: Theoretical and Empirical Considerations. British Journal of Sociology, 38(4), 445-463.

Duncan, O. D. (1966). Methodological Issues in the Analysis of Social Mobility. In N. J. Smelser, \& S. M. Lipset (Eds.), Social Structure and Mobility in Economic Development (pp. 51-97). Chicago: ALDINE Publishing Company.

Duru-Bellat, M., \& Kieffer, A. (2008). Objective/subjective: The two facets of social mobility. Sociologie du travail, 50, 1-18. 
Ellis, R. A., \& Lane, W. C. (1967). Social Mobility and Social Isolation: A Test of Sorokin's Dissociative Hypothesis. American Sociological Review, 32(2), 237-253.

Erikson, R. (1984). Social Class of Men, Women and Families. Sociology, 18(4), 500-514.

Erikson, R., \& Goldthorpe, J. H. (1985). Are American Rates of Social Mobility Exceptionally High? New Evidence on an Old Issue. European Sociological Review, 1(1), 1-22.

Erikson, R., \& Goldthorpe, J. H. (1992). The constant flux: A Study of Class Mobility in Industrial Societies. Oxford: Clarendon Press.

Erikson, R., Goldthorpe, J. H., \& Portocarero, L. (1979). Intergenerational Class Mobility in 3 Western European Societies: England, France and Sweden. British Journal of Sociology, 30(4), 415-441.

Evans, G. (1992). Testing the Validity of the Goldthorpe Class Schema. European Sociological Review, 8(3), 211-232.

Evans, G., \& Mills, C. (1998). Identifying Class Structure: A Latent Class Analysis of the Criterion-Related and Construct Validity of the Goldthorpe Class Schema. European Sociological Review, 14(1), 87106.

EVS (2016): European Values Study 2008: Integrated Dataset (EVS 2008). GESIS Data Archive, Cologne. ZA4800 Data file Version 4.0.0, https://doi.org/10.4232/1.12458.

Friedman, S. (2016). Habitus clivé and the emotional imprint of social mobility. The Sociological Review, 64(1), 129-147.

Ganzeboom, H. B. G., \& Treiman, D. J. (1996). Internationally Comparable Measures of Occupational Status for the 1988 International Standard Classification of Occupations. Social Science Research, 25(3), 201-239.

Ganzeboom, H. B., De Graaf, P. M., \& Treiman, D. J. (1992). A Standard International Socio-Economic Index of Occupational Status. Social science research, 21(1), 1-56.

Germani, G. (1966). Social and Political Consequences of Mobility. In Social Structure and Mobility in Economic Development. (pp. 364-394). Chicago: ALDINE Publishing Company.

Goldthorpe, J. H. (1983). Women and Class Analysis: in Defence of the Conventional View. Sociology, 17(4), 465-488. 
Goldthorpe, J. H. (1985). Soziale Mobilität und Klassenbildung: Zur Erneuerung einer Tradition soziologischer Forschung. In Die Analyse sozialer Ungleichheit: Kontinuität, Erneuerung, Innovation. (pp. 174-204). Opladen: Westdeutscher Verlag.

Goldthorpe, J. H. (1987). Social mobility and class structure in modern Britain (2nd ed.). Oxford: Clarendon Press.

Hadjar, A., \& Samuel, R. (2015). Does upward social mobility increase life satisfaction? A longitudinal analysis using British and Swiss panel data. Research in Social Stratification and Mobility, 39, 48-58.

Headey, B., Kelley, J., \& Wearing, A. (1993). Dimensions of Mental Health: Life Satisfaction, Positive Affect, Anxiety and Depression. Social Indicators Research, 29(1), 63-82.

Hollingshead, A. B., Ellis, R., \& Kirby, E. (1954). Social Mobility and Mental Illness. American Sociological Review, 19(5), 577-584.

Houle, J. N. (2011). The psychological impact of intragenerational social class mobility. Social Science Research, 40(3), 757-772.

Houle, J. N., \& Martin, M. A. (2011). Does intergenerational mobility shape psychological distress? Sorokin revisited. Research in Social Stratification and Mobility, 29(2), 193-203.

Jackman, M. R. (1972). Social Mobility and Attitude toward the Political System. Social Forces, 50(4), 462472.

Kelley, S., \& Kelley, C. G. E. (2009). Subjective social mobility: data from 30 nations. In M. Haller, R. Jowell, \& T. W. Smith (Eds.), Charting the Globe: The International Social Survey Programme 19842009. London: Routledge.

Kessin, K. (1971). Social and Psychological Consequences of Intergenerational Occupational Mobility. American Journal of Sociology, 77(1), 1-18.

Kingston, P. W. (2000). The Classless Society. California: Stanford University Press.

Lubrano, A. (2004). Limbo: Blue-collar roots, white-collar dreams. New Jersey: John Wiley \& Sons.

Marshall, G., \& Firth, D. (1999). Social mobility and personal satisfaction: evidence from ten countries. British Journal of Sociology, 50(1), 28-48.

Marshall, G., Roberts, S., \& Burgoyne, C. (1996). Social class and Underclass in Britain and the USA. British Journal of Sociology, 47(1), 22-44. 
Missinne, S., Daenekindt, S., \& Bracke, P. (2015). The social gradient in preventive healthcare use: what can we learn from socially mobile individuals? Sociology of Health \& Illness, 37(6), 823-838.

Myers, D. G., \& Diener, E. (1995). Who Is Happy? Psychological Science, 6(1), 10-19.

Newman, K. S. (1988). Falling from grace: The Experience of Downward Mobility in the American Middle Class. New York: Free Press.

Nieuwbeerta, P., de Graaf, N. D., \& Ultee, W. (2000). The Effects of Class Mobility on Class Voting in PostWar Western Industrialized Countries. European Sociological Review, 16(4), 327-348.

Präg P, Richards L. (2018). Intergenerational social mobility and allostatic load in Great Britain. Journal of Epidemiology and Community Health, https://dx.doi.org/10.1136/jech-2017-210171.

Schuck, B., \& Steiber, N. (2017). Does Intergenerational Educational Mobility Shape the Well-Being of Young Europeans? Evidence from the European Social Survey. Social Indicators Research, https://doi.org/10.1007/s11205-017-1753-7.

Sobel, M. E. (1981). Diagonal Mobility Models: A Substantively Motivated Class of Designs for the Analysis of Mobility Effects. American Sociological Review, 46(6), 893-906.

Sobel, M. E. (1985). Social Mobility and Fertility Revisited: Some New Models for the Analysis of the Mobility Effects Hypothesis. American Sociological Review, 50(5), 699-712.

Sørensen, A. (1994). Women, Family and Class. Annual Review of Sociology, 20, 27-45.

Sorokin, P. A. (1927). Social Mobility. New York: Harper and Brothers.

Stansfeld, S. A., Head, J., \& Marmot, M. G. (1998). Explaining social class differences in depression and wellbeing. Social Psychiatry and Psychiatric Epidemiology, 33, 1-9.

Tolsma, J., de Graaf, N. D., \& Quillian, L. (2009). Does intergenerational social mobility affect antagonistic attitudes towards ethnic minorities? British Journal of Sociology, 60(2), 257-277.

Tumin, M. M., \& Collins, R. C. (1959). Status, Mobility and Anomie: A Study in Readiness for Desegregation. British Journal of Sociology, 10(3), 253-267.

van der Waal, J., Daenekindt, S., \& de Koster, W. (2017). Statistical challenges in modelling the health consequences of social mobility: the need for diagonal reference models. International journal of public health, 62(9), 1029-1037. 
van Eijck, K. (1999). Socialization, education, and lifestyle: How social mobility increases the cultural heterogeneity of status groups. Poetics, 26(5-6), 309-328.

Zang, E., \& de Graaf, N. D. (2016). Frustrated Achievers or Satisfied Losers? Inter- and Intragenerational Social Mobility and Happiness in China. Sociological Science, 3, 779-800.

Zhao, Y. Z., Li, Y. J., Heath, A., \& Shryane, N. (2017). Inter- and intra-generational social mobility effects on subjective well-being - Evidence from mainland China. Research in Social Stratification and Mobility, 48, 54-66. 
Tables

Table 1: Country descriptive statistics.

\begin{tabular}{|c|c|c|c|c|}
\hline Country & $\begin{array}{l}\text { Mean life } \\
\text { satisfaction }\end{array}$ & $\begin{array}{l}\text { \% Upward mobility } \\
\text { (quarter) }\end{array}$ & $\begin{array}{l}\text { \% Downward } \\
\text { mobility (quarter) }\end{array}$ & $\overline{\mathrm{N}}$ \\
\hline Albania & 6.211 & $37.950(2)$ & $14.499(2)$ & 666 \\
\hline Armenia & 5.379 & $40.310(3)$ & $11.887(1)$ & 782 \\
\hline Austria & 7.690 & $38.713(2)$ & $12.972(1)$ & 1017 \\
\hline Belgium & 7.664 & $36.232(2)$ & $16.907(3)$ & 1061 \\
\hline Bosnia and Herzegovina & 7.157 & $46.253(4)$ & $14.736(2)$ & 456 \\
\hline Bulgaria & 5.588 & $33.666(1)$ & $13.374(1)$ & 1038 \\
\hline Belarus & 6.018 & $42.791(4)$ & $11.800(1)$ & 765 \\
\hline Croatia & 7.129 & $42.090(4)$ & $12.640(1)$ & 612 \\
\hline Cyprus & 7.526 & $40.511(4)$ & $20.744(4)$ & 612 \\
\hline Czech Republic & 7.104 & $39.410(3)$ & $12.020(1)$ & 1123 \\
\hline Denmark & 8.383 & $38.214(2)$ & $18.879(4)$ & 1047 \\
\hline Estonia & 6.530 & $39.601(3)$ & $15.059(3)$ & 1037 \\
\hline Finland & 7.826 & $45.679(4)$ & $13.462(2)$ & 759 \\
\hline France & 6.992 & $36.831(2)$ & $16.443(3)$ & 1055 \\
\hline Georgia & 5.349 & $36.069(1)$ & $16.053(3)$ & 837 \\
\hline Germany & 7.145 & $41.380(4)$ & $14.281(2)$ & 1281 \\
\hline Great-Britain & 7.514 & $38.505(2)$ & $17.740(4)$ & 1054 \\
\hline Greece & 6.864 & $27.500(1)$ & $19.600(4)$ & 875 \\
\hline Hungary & 6.172 & $37.432(2)$ & $14.724(2)$ & 991 \\
\hline Iceland & 8.021 & $38.061(2)$ & $22.253(4)$ & 455 \\
\hline Ireland & 7.798 & $42.754(4)$ & $11.512(1)$ & 510 \\
\hline Italy & 7.245 & $39.045(3)$ & $14.459(2)$ & 859 \\
\hline Kosovo & 6.976 & $45.608(4)$ & $12.839(1)$ & 245 \\
\hline Latvia & 6.094 & $39.269(3)$ & $17.629(4)$ & 882 \\
\hline Lithuania & 6.216 & $39.178(3)$ & $12.166(1)$ & 851 \\
\hline Luxembourg & 7.886 & $38.436(2)$ & $16.887(3)$ & 1102 \\
\hline Macedonia & 6.851 & $39.750(3)$ & $16.696(3)$ & 516 \\
\hline Malta & 7.991 & $32.785(1)$ & $18.600(4)$ & 927 \\
\hline Moldova & 6.423 & $39.910(3)$ & $9.281(1)$ & 846 \\
\hline Montenegro & 7.412 & $38.832(3)$ & $16.944(4)$ & 515 \\
\hline Netherlands & 7.993 & $37.644(2)$ & $16.351(3)$ & 1120 \\
\hline Norway & 8.119 & $41.410(4)$ & $18.301(4)$ & 768 \\
\hline Poland & 7.118 & $35.648(1)$ & $16.140(3)$ & 804 \\
\hline Portugal & 6.742 & $35.803(1)$ & $14.887(2)$ & 902 \\
\hline Romania & 6.839 & $35.743(1)$ & $14.004(2)$ & 551 \\
\hline Russian Federation & 6.414 & $35.183(1)$ & $14.106(2)$ & 909 \\
\hline Serbia & 6.797 & $39.338(3)$ & 17.499 (4) & 622 \\
\hline Slovak Republic & 7.294 & $37.986(2)$ & $9.151(1)$ & 995 \\
\hline Slovenia & 7.594 & $41.522(4)$ & $14.399(2)$ & 696 \\
\hline Spain & 7.255 & $32.532(1)$ & $16.129(3)$ & 869 \\
\hline Sweden & 7.771 & $39.366(3)$ & $16.257(3)$ & 742 \\
\hline Switzerland & 8.013 & $42.658(4)$ & $15.229(3)$ & 897 \\
\hline Turkey & 6.195 & $22.013(1)$ & $27.803(4)$ & 694 \\
\hline Ukraine & 5.736 & $36.161(1)$ & $14.838(2)$ & 1022 \\
\hline
\end{tabular}

Calculations based on weighted data; selected age $>=30$ 
Table 2: Parameter estimates from the Diagonal Reference Model for dependent life satisfaction across countries categorized according to downward mobility rates and upward mobility rates.

\begin{tabular}{|c|c|c|c|c|}
\hline $\begin{array}{l}\text { Country groups } \\
\text { according to downward } \\
\text { mobility rates }\end{array}$ & Lowest quarter & Second quarter & Third quarter & Highest quarter \\
\hline \multicolumn{5}{|l|}{ Diagonal intercepts } \\
\hline$\mu 11$ : Service class & $6.778(.151)^{* * *}$ & $7.631(.139)^{* * *}$ & $7.935(.117)^{* * *}$ & $6.894(.137)^{* * *}$ \\
\hline$\mu 22:$ Intermediate class & $6.638(.163)^{* * *}$ & $7.398(.137)^{* * *}$ & $7.790(.123)^{* * *}$ & $6.693(.134)^{* * *}$ \\
\hline $\begin{array}{l}\mu 33 \text { : Working class } \\
\text { Weight parameter }\end{array}$ & $6.121(.146)^{* * *}$ & $7.008(.132)^{* * *}$ & $7.443(.122)^{* * *}$ & $6.557(.139)^{* * *}$ \\
\hline $\begin{array}{l}\text { Origin }(\mathrm{p})^{\mathrm{a}} \\
\text { Mobility effects } \\
\text { (Ref=immobile) }\end{array}$ & $.590(.195)$ & $.322(.214)$ & $.404(.199)$ & $.000(.431)$ \\
\hline Upward & $.147(.117)$ & $.065(.107)$ & $.124(.080)$ & $.095(.106)$ \\
\hline Downward & $-.172(.112)$ & $-.008(.107)$ & $.006(.082)$ & $-.022(.101)$ \\
\hline $\begin{array}{l}\text { Country groups } \\
\text { according to upward } \\
\text { mobility rates }\end{array}$ & Lowest quarter & Second quarter & Third quarter & Highest quarter \\
\hline \multicolumn{5}{|l|}{ Diagonal intercepts } \\
\hline$\mu 11:$ Service class & $6.921(.140)^{* * *}$ & $8.000(.113)^{* * *}$ & $6.292(.154)^{* * *}$ & $7.826(.148)^{* * *}$ \\
\hline$\mu 22$ : Intermediate class & $6.640(.142)^{* * *}$ & $7.825(.115)^{* * *}$ & $6.023(.159) * * *$ & $7.685(.150)^{* * *}$ \\
\hline $\begin{array}{l}\mu 33 \text { : Working class } \\
\text { Weight parameter }\end{array}$ & $6.384(.136)^{* * *}$ & $7.545(.117)^{* * *}$ & $5.687(.155)^{* * *}$ & $7.294(.145)^{* * *}$ \\
\hline $\begin{array}{l}\text { Origin }(\mathrm{p})^{\mathrm{a}} \\
\text { Mobility effects } \\
(\text { Ref }=\text { immobile) }\end{array}$ & $.179(.287)$ & $.183(.239)$ & $.133(.243)$ & $.443(.201)$ \\
\hline Upward & $.070(.115)$ & $.058(.084)$ & $.012(.120)$ & $.100(.089)$ \\
\hline Downward & $.086(.111)$ & $.083(.084)$ & $.001(.115)$ & $-.150(.094)$ \\
\hline
\end{tabular}

Analyses performed using SPSS 24; Weighted analyses; Selected age $>=30 ;{ }^{a}=$ none of the weight parameters are significantly different from 0.5 based on the $95 \%$ confidence interval; All models are controlled for gender, age, employment status and country dummies; $*=p<.05 ; * *=p<.01$; *** $=$ $p<.001$ 